\title{
Review: debridement using hydrogel appears to be more effective than standard wound care for healing diabetic foot ulcers
}

Smith J. Debridement of diabetic foot ulcers. Cochrane Database Syst Rev 2002;(4):CD003556 (latest version 27 Aug 2002).

\section{QUESTION: What is the effectiveness of different debridement methods for diabetic foot ulcers?}

\section{Data sources}

Studies were identified by searching the Specialised Trials Register of the Cochrane Wounds Group, which is compiled by searching MEDLINE, EMBASE/Excerpta Medica, CINAHL, and the Cochrane Controlled Trials Register (up to January 2000); scanning bibliographies of relevant studies; and contacting experts in the field.

\section{Study selection}

Studies were selected if they were randomised controlled trials (RCTs) that included patients with type 1 or 2 diabetes with active foot ulcers, assessed the effectiveness of treatment with any debridement method compared with no debridement or other debridement methods, and measured complete wound closure or rate of reduction in wound size.

\section{Data extraction}

Data were extracted on patients, study design and quality, interventions, and outcomes (complete wound closure, rate of reduction in wound size, proportion of ulcers recurring after healing, quality of life, and adverse events).

\section{Main results}

5 RCTs met the selection criteria. 3 trials compared hydrogel as a method of debridement with standard wound care (good wound care or gauze). 1 trial compared hydrogel with larval therapy. 1 trial compared surgical debridement with conservative care. In all 5 trials, the primary outcome was complete wound closure. Sample sizes ranged from 29 to 172 patients. In 4 studies, follow up durations ranged from 3 to 6 months.

Meta-analysis of 3 studies showed that hydrogel was associated with a greater proportion of ulcers completely healed and fewer complications than standard wound care (table). In 1 study, larvae and hydrogel did not differ for proportion of ulcers completely healed ( $7 \%$ \% $3 \%$, follow up duration not reported). In 1 trial, surgical debridement and conservative care did not differ for proportion of ulcers completely healed $(95 \% v$ $79 \%, \mathrm{p}=0.1)$, recurrence rates $(14 \%$ v $33 \%, \mathrm{p}=0.14)$, or complication rates $(5 \% v 13 \%, \mathrm{p}=0.4)$ at 6 months.

\section{Conclusion}

In patients with diabetic foot ulcers, debridement using hydrogel appears to be more effective than standard wound care for wound healing and is associated with fewer complications.
Debridement using hydrogel v using standard wound care in diabetic foot ulcers at approximately 3-5 months follow up (3 trials)*

\begin{tabular}{|c|c|c|c|c|}
\hline \multirow[b]{2}{*}{ Outcomes } & \multicolumn{2}{|c|}{ Weighted event rates } & \multirow[b]{2}{*}{ RBI $(95 \% \mathrm{Cl})$} & \multirow[b]{2}{*}{ NNT (Cl) } \\
\hline & Hydrogel & $\begin{array}{l}\text { Standard } \\
\text { care }\end{array}$ & & \\
\hline \multirow[t]{2}{*}{$\begin{array}{l}\text { Complete wound } \\
\text { healing }\end{array}$} & $52 \%$ & $28 \%$ & $84 \%$ (30 to 161$)$ & 5 (2 to 10$)$ \\
\hline & & & RRR (Cl) & NNH (Cl) \\
\hline Complications & $21 \%$ & $36 \%$ & $40 \%$ (5 to 62 ) & $7(4$ to 31$)$ \\
\hline
\end{tabular}

*Abbreviations defined in glossary; RBI, RRR, NNT, NNH, and Cls calculated from data in article using a fixed effects model.

\section{COMMENTARY}

Approximately $2 \%$ of the population in the UK has diabetes, of whom $15 \%$ will develop foot ulceration. ${ }^{1}$ Foot ulcers are difficult to heal (only $31 \%$ of ulcers are healed after 20 wks of good wound care $)^{2}$ and are frequently a precursor to amputation. ${ }^{3}$ Debridement (removal of slough and necrotic tissue) and off loading are the main treatments for foot ulceration in diabetes, but uncertainty exists about the most effective method for achieving a clean, healing ulcer. Smith identified only 5 RCTs that address this question. Unfortunately, little information exists about where studies were done (country or setting) or cointerventions, such as off loading, making the results of the review more difficult to interpret and apply. Descriptions of study participants (eg, extent of arterial disease and glycaemic control) were also sparse. These are likely failings of the primary reports rather than the review process.

In the review by Smith, the results of the 3 trials comparing hydrogels with standard care or gauze dressings were pooled despite the controls being somewhat different. However, the results were so consistent that it is unlikely that this would have influenced the findings. The review suggests that hydrogels increase the proportion of foot ulcers completely healed within 3-5 months compared with standard care or gauze dressings. The extent to which this increased healing is a consequence of debridement is not clear. Hydrogels provide a moist healing environment, and the effect may be caused by debridement, moisture, or an interaction between the 2 .

Because evidence for the different methods of debridement is so sparse, the type of debridement chosen in practice will depend on many factors including patient acceptability, status of the ulcer, practitioner skills, and the products available.

The results of this review will be useful to all nurses who treat people with diabetes who have foot ulcers. Although further research is needed to clarify the relation between debridement and wound healing, hydrogels offer healing advantages over gauze, are low cost, easy to use, and carry minimal risk of complications.

Liz Scanlon, RGN, RM, MSc Nurse Consultant - Tissue Viability Leeds North West Primary Care Trust Leeds, UK

1 Calman K. On the state of the public health. The annual report of the Chief Medical Officer of the Department of Health for the year 1997. The Stationery Office, 1998. http://www.doh.gov.uk/ cmo/rep97.htm

2 Margolis DJ, Kantor J, Berlin JA. Healing of diabetic neuropathic foot ulcers receiving standard treatment. A meta-analysis. Diabetes Care 1999;22:692-5.

3 Pecoraro RE, Reiber GE, Burgess EM. Pathways to diabetic limb amputation. Basis for prevention. Diabetes Care 1990;13:513-21. 